\title{
Type 2 diabetes patients assessment of the COMODITY12 mHealth system
}

\author{
Przemysław KARDAS \\ I Deptartment of Family Medicine, \\ Medical University of Lodz, Poland \\ e-mail: przemyslaw.kardas@umed.lodz.pl
}

\author{
Krzysztof LEWANDOWSKI \\ Department of Endocrinology \& Metabolic Diseases, \\ Medical University of Lodz, Poland \\ e-mail: lewandowski@doctors.org.uk
}

\begin{abstract}
Patient acceptance is one of the major barriers toward widespread use of mHealth. The aim of this study was to assess patients' experience with their use of COMMODITY12 telehealth system.

DM2 patients assessed COMMODITY12 system after its 6 weeks' long use within clinical trial. Patients opinions were collected with 7-item questionnaire, assessing different aspects of system use, as well as EuroQol-5D-5L generic questionnaire, assessing health-related quality of life.
\end{abstract}

Thirty patients (female, 13, male, 17, mean age +/- SD 59.9 +/5.3) completed study. All dimensions of experience with system use were assessed well, with maximum values for clearness of instructions, and ease of use (4.80, and 4.63, respectively). Health related quality of life, as assessed with general utility measure, improved significantly $(\mathbf{P}<\mathbf{0 . 0 5})$.

Study proved that the COMODITY12 system is accepted well by type 2 diabetes patients taking part in clinical trial. Nevertheless, before future commercialisation of the system, several minor problems identified during the study need to be addressed.

\section{Keywords-mHealth, COMODITY12, diabetes}

\section{BACKGROUND}

Diabetes mellitus (DM), commonly referred to as diabetes, is a group of metabolic diseases characterized by high blood glucose level over a prolonged time. Diabetes occurs in the individual if the pancreas is not producing enough insulin (glucose level-lowering hormone), or the cells of the body are not responding properly to the insulin (the phenomenon known as insulin resistance). Three main types of diabetes mellitus include:

- Type 1 diabetes (DM1), previously referred to as insulindependent diabetes, which results from the failure to produce insulin due to autoimmune destruction of pancreatic beta cells, with peak of onset in children and adolescents

- Type 2 diabetes (DM2), caused primarily by insulin resistance, due to obesity and lack of physical activity, previously referred to as "non insulin-dependent diabetes mellitus', mostly prevalent in older adults, and elderly
- Gestational diabetes, occurring in previously diabetes-free pregnant women. This entity includes states of glucose intolerance presenting particularly in the third trimester of pregnancy.

Due to its high prevalence, as well as a number of health, and economic consequences, diabetes mellitus stands for the major public health problem worldwide. Currently, the number of those affected approaches 400 million (of which app. $90 \%$ are DM2 cases), what equals to app. $8.3 \%$ of global adult population. However, according to the International Diabetes Federation projections, this number will continue to grow, and is expected to reach 592 million by 2035 [1]. Distant health consequences of diabetes are multiple, and include micro- and macroangiopathy, with clinical manifestation of coronary artery disease, myocardial infarction and stroke, as well as retinopathy, nephropathy, and nephropathy. In the short run, abnormal glucose values may lead to life-threatening conditions of hypo- and hyperglycaemia, and coma. In 2013, healthcare spending on diabetes were estimated to reach USD 548 billion, whereas the global economic cost of diabetes in 2014 was estimated to be 612 billion USD [2].

In type 1 diabetes, and gestational diabetes, insulin is the standard treatment. Due to the achievements of modern genetics, man-made human insulin is widely available, and recently, artificial proteins, with insulin-mimicking activity, have been developed. Unfortunately, all these proteins are inactivated in human digestive system. Therefore, injections remain standard route of administration of these drugs (only recently, inhaled insulin has been reintroduced to the market). On the contrary, most DM2 patients are effectively treated with oral medication, while only some require concurrent insulin. Regardless of the type of the diabetes, and specific medications, treatment plan should include special diet (no sugar/simple carbohydrates, limited calories), physical exercise, tobacco and alcohol avoidance as well as maintaining normal body weight.

Diabetic patients are nowadays expected to actively participate in their treatment: daily self-management activities include glucose self-monitoring, frequent blood pressure check-ups and foot inspections are also advisable. Those taking insulin, have to adjust its dosage according to current glucose level, taking into account expected glucose burn out due to physical activity, and glucose supply due to dietary 
intake. Several lab-based tests are also in place to assess longterm glucose control, as well as to screen for diabetes complication. Not surprisingly, every patient spends reasonable long time daily on diabetes self-care; in a survey in the US it was found to be 58 minutes/day on average [3].

In order to help those suffering from diabetes mellitus, a number of novel solutions have been developed. These, among others, include, telemedicine systems designed to improve and ease patients' self-management of diabetes as well as to provide healthcare professionals with continuous access to patient data. One of such modern solutions is COMMODITY12 telemedicine system, being result of multinational European collaboration [4].

COMMODITY12 Project aimed to design, build, and validate an intelligent system for the multi-layered analysis of multi-parametric medical data related to management of diabetes type 1 and 2 . In order to achieve this goal, the COMMODITY12 architecture consists of 4 layers: the BodyArea-Network (BAN), Smart Hub Layer, (SHL), data representation and retrieval layer (DDR), and finally, Artificial Intelligence Layer (AIL) (see Picture 1). The role of the BAN is the acquisition of multi-parametric data concerning monitoring of diabetes (glucose) and comorbidities (pressure, heart rate and rhythm, weight, respiratory rate and rhythm, patient adherence to medication, symptoms). BAN is composed of:

- Gluco-Tel ${ }^{\mathrm{TM}}$ (BodyTel Europe GmbH, Bad Wildungen, Germany) - a Bluetooth-enabled glucometer

- Pressure-Tel ${ }^{\mathrm{TM}}$ (BodyTel Europe GmbH, Bad Wildungen, Germany) - a Bluetooth-enabled blood pressure reader

- Weight-Tel ${ }^{\mathrm{TM}}$ (BodyTel Europe GmbH, Bad Wildungen, Germany) - a Bluetooth-enabled scale

- $\quad$ BioHarness ${ }^{\mathrm{TM}}$ (Zephyr Technology, Annapolis, Maryland, USA) - a Bluetooth-enabled of ECG, heart rhythm, and respiratory movements

- MEMS $^{\text {тм }}$ (MeadWestvaco Corporation, Richmond, VA, USA) - a patient adherence monitor

- A triaxial accelerometer - already built in the SmartHub (mobile phone) assessing the patient's movements will be installed on the smartphone.

The use of such systems could be, however, limited by a number of factors, of which patient acceptance stands for major one. This might be particularly true for DM2 patients, who are on average older, and due to this, less inclined to use eHealth and eHealth solutions. Besides, not every parameter is of obvious interest of DM2 patients: they are used to measure they glucose level from time to time, but not necessarily on a daily basis. Unless they develop cardiovascular conditions, they may be much less interested in reading their blood pressure, and ECG. Finally, they might be completely not interested in objective measurements of their weight, and adherence level, as deviation from both diet and medication is a frequent phenomenon in these patients.
In this paper we describe results of patients' assessment of their experience with COMMODITY12 system use within six weeks' long clinical trial in DM2 patients - the 'COMMODITY2' trial.

\section{METHODS}

COMMODITY2 trial was a feasibility parallel-arm randomized controlled trial in outpatients diagnosed with DM2. Inclusion criteria included age 18-65 years, diabetes type 2 diagnosed $\geq 6$ months prior to the study, currently in the maintenance phase of treatment (of which at least a part consisted of the use of metformin for daily treatment, with a daily dose of $\geq 500 \mathrm{mg}$ ), and ability to use the cell phone and the sensors (as committed by the patient). Patients enrolled in the trial were randomly ascribed for 6 weeks to either control, or intervention arm, where they were using COMMODITY12 telemedicine system.

In the intervention arm, patients were equipped with COMMODITY12 system, composed of smart phone, and a number of sensors described above. MEMS sensor was used to assess patient adherence with oral antidiabetic agents they were using (Metformin). Being provided with written materials, and 1.5 hour long individual training session by study assistant, as well as an opportunity to call an assistant in the case of need, they were expected to take several daily measurements (Table 1). Of a note is that within this trial, not all the COMMODITY12 system functionalities were enabled to the patients, these being, inter allia, system-generated alerts, patient feedback, and direct access to web-based patient data repository. This decision was taken due to the fact that the full analysis of the performance of these functionalities must precede their implementation in real life conditions. However, within COMODITY2 trial, the COMODITY12 system was only tested on real patients for the first time.

After completion of 6 weeks' long period of trial, patients were asked to assess their experience with COMODITY12 system use with the means of a 7-item questionnaire, assessing different aspects of system use with 5-level Likert scales (e.g. from 'very good' to 'very bad', 5 items in total), and with open questions ( 2 items in total). Moreover, patient health-related quality of life was assessed at the entry, and study end with EuroQol-5D-5L questionnaire, which assesses dimensions of health with 5-level Likert scale (the labels for each of the dimensions are: no problems, slight problems, moderate problems, severe problems and unable to/extreme problems), as well as the health state in general with visual analogue scale (range $0-100$ ). Out of the 5 dimensions of EuroQol-5D-5L health-related quality of life, index-based values ('utilities') have been calculated, using UK value set (due to lack of relevant value set for Polish population at the course of the study), with "crosswalk" methodology between already available EQ-5D-3L value sets, and the newly elaborated EQ5D-5L descriptive system [5]. 
TABLE I. SCHEDULE OF SELF-MEASUREMENTS IN THE INTERVENTION GROUP.

\begin{tabular}{|c|c|}
\hline Measures & Measuring time and frequency \\
\hline Pressure-Tel & $2 \mathrm{x} /$ day (morning, and $1 / 2 \mathrm{~h}$ after evening meal) \\
\hline Weight-Tel & $1 \mathrm{x} /$ day, in the morning \\
\hline Gluco-Tel & $\begin{array}{l}\text { once a month: } 6 \mathrm{x} / \text { day; daily: } 3 \mathrm{x} / \text { day (even days: prior to } \\
\text { breakfast / lunch / dinner, uneven days: } 1-2 \mathrm{~h} \text { after } \\
\text { breakfast / lunch / dinner) }\end{array}$ \\
\hline Bioharness & $\begin{array}{l}\text { at least } 2 \mathrm{x} / \text { week during } 6 \text { hours (1x during the day/ } 1 \mathrm{x} \\
\text { at night) }\end{array}$ \\
\hline MEMS & continuously for the first 6 weeks of the trial \\
\hline
\end{tabular}

Descriptive statistics was used to present study findings. For calculating statistics of patient assessment of their experience with the system, Likert scale values were translated into digital values, with 5 representing maximal value, and 1 - minimal one. For comparison of pre- and post-intervention results of EuroQol-5D-5L, Wilcoxon signed-rank test was used (normal distribution of values being excluded with Shapiro- Wilk test).

\section{RESULTS}

Thirty patients (female, 13, male, 17, mean age +/- SD $59.9+/-$ 5.3) from intervention arm completed trial according to the study protocol, and provided their assessment of COMMODITY12 system, as detailed in Table 2.

System users asked for its strengths provided most often their comments in terms of:

- $\quad$ 'the system being fast' (5 patients)

- 'system enabled them systematic self-monitoring' (5 patients)

- $\quad$ 'system was easy to use' (5 patients)

TABLE II.

PATIENTS' ASSESSMENT OF THE COMMODITY12 TELEHEALTH SYSTEM USE.

\begin{tabular}{|l|l|}
\hline Measures & \multicolumn{1}{|c|}{ Measuring time and frequency } \\
\hline Pressure-Tel & 2x/day (morning, and 1/2 h after evening meal) \\
\hline Weight-Tel & 1x/day, in the morning \\
\hline Gluco-Tel & $\begin{array}{l}\text { once a month: } 6 \mathrm{x} / \text { day; daily: 3x/day (even days: prior to } \\
\text { breakfast / lunch / dinner, uneven days: 1-2 h after } \\
\text { breakfast / lunch / dinner) }\end{array}$ \\
\hline Bioharness & $\begin{array}{l}\text { at least } 2 \mathrm{x} / \text { week during } 6 \text { hours (1x during the day/ } 1 \mathrm{x} \\
\text { at night) }\end{array}$ \\
\hline MEMS & \begin{tabular}{l} 
continuously for the first 6 weeks of the trial \\
\hline
\end{tabular}
\end{tabular}

$\mathrm{x}$ - mean, SD - standard deviation.* - dimensions have been assessed with 5-level Likert scales, 5 represents maximal value, $1-$ minimal
TABLE III PATIENTS' ASSESSMENT OF THEIR HEALTH-RELATED QUALITY OF LIFE, AS ASSESSED WITH EUROQOL-5D-5L QUESTIONNAIRE.

\begin{tabular}{|l|c|c|c|c|c|c|}
\hline \multirow{2}{*}{$\begin{array}{c}\text { Health- } \\
\text { related } \\
\text { quality of } \\
\begin{array}{c}\text { life } \\
\text { dimension }\end{array}\end{array}$} & \multicolumn{2}{|c|}{$\begin{array}{c}\text { Prior to the } \\
\text { system use }\end{array}$} & \multicolumn{2}{|c|}{ Post-system use } & $\begin{array}{c}\text { z test } \\
\text { value }\end{array}$ & $\begin{array}{c}\text { P } \\
\text { value }\end{array}$ \\
\cline { 2 - 5 } & $\mathbf{x}$ & SD & $\mathbf{x}$ & SD & \\
\hline Mobility* & 1.73 & 1.01 & 1.80 & 1.03 & 0.489 & $\mathrm{P}>0.05$ \\
\hline Self-Care* & 1.30 & 0.65 & 1.27 & 0.58 & 0.535 & $\mathrm{P}>0.05$ \\
\hline $\begin{array}{l}\text { Usual } \\
\text { activities* }\end{array}$ & 1.43 & 0.82 & 1.40 & 0.72 & 0.405 & $\mathrm{P}>0.05$ \\
\hline $\begin{array}{l}\text { Pain/disco } \\
\text { mfort* }\end{array}$ & 2.17 & 0.99 & 2.03 & 1.00 & 1.121 & $\mathrm{P}>0.05$ \\
\hline $\begin{array}{l}\text { Anxiety/de } \\
\text { pression* }\end{array}$ & 1.87 & 1.04 & 1.77 & 0.94 & 0.764 & $\mathrm{P}>0.05$ \\
\hline $\begin{array}{l}\text { Index- } \\
\text { based } \\
\text { value }\end{array}$ & 0.723 & 0.25 & 0.762 & 0.222 & 2.053 & $\mathrm{P}<0.05$ \\
\hline $\begin{array}{l}\text { Health } \\
\text { state }\end{array}$ & 72.59 & 20.81 & 77.52 & 16.86 & 1.834 & $\mathrm{P}>0.05$ \\
\hline
\end{tabular}

$\mathrm{x}$ - mean, SD - standard deviatio

- parameters have been assessed with 5-level Likert scales, 1 representing maximal value, 5 - minima one; \# - Index-based values have been calculated with "crosswalk" methodology, see Methods section for details: ${ }^{\$}$ - as assessed with visual analogue scale (range $0-100$ ).

Less than half of users (14 in total) provided their comments on weaknesses of the system, pointing to 'frequent need to recharge' ( 2 patients), and problems with glucometer strips (2 patients).

Minor improvements were observed in four out of the five dimensions of health-related quality of life (self-Care, usual activities, pain/discomfort, and anxiety/depression). Neither these changes, nor the health state, as assessed with visual scale, reached, however, the level of the statistical significance. Despite that, the cumulative utility measure (index-based value) demonstrated significant improvement in health-related quality of life (Table 3).

\section{DISCUSSION}

So far, there has been limited amount of research done exploring the use of mobile technologies in order to improve diabetes care [6]. Review of similar systems, performed during Clustering event 'Ambient Intelligence Advanced Technologies in Support of Healthcare and Assisted Living' (Heraklion, Greece, 26-27th September 2013) prove that the COMMODITY12 system is probably the most comprehensive mHealth system developed with EU support.

Nevertheless, patients acceptance seems to be one of the major barriers preventing wider implementation of the mHealth systems. The problem seems to be twofold. At first, patients have to possess certain level of general ICT literacy, and self-confidence in their ability to operate computers, and mobile solutions. Furthermore, they have to cope with specific problems arising from the use of particular system, such as the need to e.g. recharge, restart and/or connect sensors, etc.

DM2 predominantly develops in older adults, and elderly. Patients at that age could be expected to have less experience with computers and the use of mobile solutions. Despite rather high age of the study participants (60 years, on average), their 
assessment of the COMMODITY12 telehealth system was remarkably positive - with all dimensions reaching mean values of above four in five-point scale, and maximum values for clearness of instructions, and ease of use (4.80, and 4.63, respectively). The free text comments provided by the participants confirmed that image, pointing most often at such aspects as the system being easy to use, fast, and focused to enable them to perform systematic self-monitoring.

Health-related quality of life may stand for another, indirect measure of COMMODITY12 system positive effect on the study participants. Although its effect on individual dimensions was only minor, the change of general utility measure ('index-based values') reached, however, the level of statistical significance at $\mathrm{P}<0.05$, regardless of the fact that the study was not powered to expect reaching such a difference for sure. One may expect that with such a positive change, users will be happy to accept the telehealth system well.

Relatively good acceptance of the COODITY12 by patients might be partly related to the fact that prior to the final system architecture designed was set, a careful assessment of end-users needs, and expectations from the telehealth system was performed under the scenario of focusgroup study [7].

Nevertheless, some specific comments provided by patients on problems encountered with COMMODITY12 system use need to be taken into consideration, and addressed before future commercialisation of the system. In particular, this addresses the reliability of the system, and results in the first instance from problems with glucometer, and strips use. Glucose measurements play central part in the system architecture, as maintenance of glucose homeostasis is of crucial importance for DM management

When assessing the results of this study, one has to be aware of its limitations. In fact, one of the inclusion criteria was ability to use the cell phone and the sensors. However, this was only committed by the patient, and not tested a priori in anyway. Assuming that nowadays vast majority of the westernised populations, including elderly, is using mobile phones on a daily basis, this does not seem to be the major barrier precluding extrapolation of study findings.

Of course, patient assessment of the telehealth system is not the end of the story. In his recent review on mHealth, Klonoff pointed at the three additional hurdles that must be overcome to facilitate widespread adoption of this technology, i.e. (1) privacy to satisfy regulators, (2) clinical benefit to satisfy clinicians, and (3) economic benefit to satisfy payers. [8]. All these have been tested for COMMODITY12, and the data are currently under elaboration. Moreover, scaling up the intervention is another bottleneck, and a lot has to be done to assure its success, as Health is not a 'silver bullet' [9]. Nevertheless, finally only the end users would be the ones who decide on the market success of such a solution. Despite the above-mentioned limitations, data collected in this study prove that for a significant number of diabetic patients, COMMODITY12 system could be easy-to-accept natural turn.

Lessons learned from this study might be also of value for another eHealth and eHealth initiatives. Clear definition of the final end-users, assessment of their needs and expectations on the early stage of the project development, and several rounds of iterative cycles of 'testing performance - analysing results defining necessary improvements - adopting modifications' in healthy volunteers/fake patients (in COMMODITY12 we did 5 such rounds), prior to exposing real patients to the interactions with a system, is just a must. Finally, none medical device, nor eHealth/mHealth system would be accepted by all the relevant patients. The challenge is, however, to build the system the will be of real help for high enough number of patients.

Picture $1 . \quad$ COMMODITY12 SYSTEM IN A GLANCE.
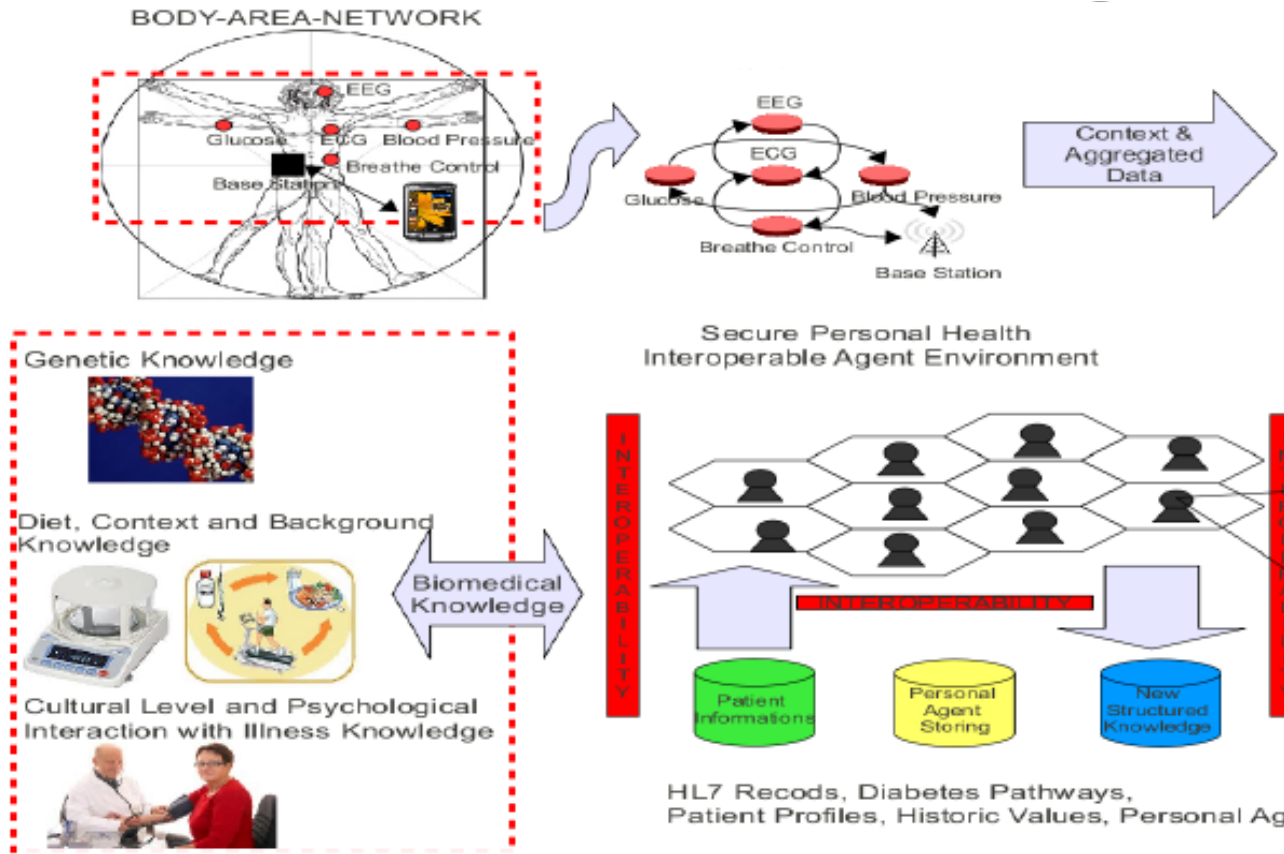

Secure Multi-Parametric Mobile Machine Learning

Secure Personal Health Interoperable Agent Environment

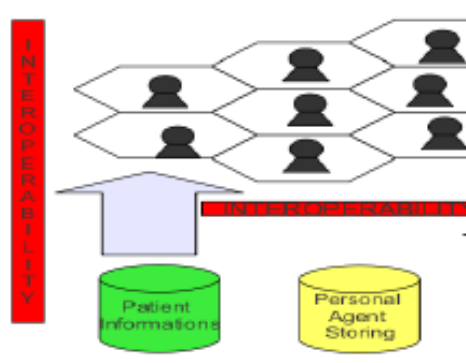

HL7 Recods, Diabetes Pathways,

Patient Profiles, Historic Values, Personal Agents 


\section{ACKNOWLEDGMENTS}

This work was partially supported by the EU FP7 Project COMMODITY12 (www.commodity12.eu).

\section{REFERENCES}

[1] Shi Y, Hu FB. The global implications of diabetes and cancer. Lancet. 2014 Jun 7;383(9933):1947-8.

[2] IDF DIABETES ATLAS (6th ed.). International Diabetes Federation. 2013. p. 7. ISBN 2930229853.

[3] Safford MM, Russell L, Suh DC, Roman S, Pogach L. How much time do patients with diabetes spend on self-care? J Am Board Fam Pract. 2005;18(4):262-70.

[4] Kafali O, Bromuri S, Sindlar M, et al. COMMODITY12: A smart ehealth environment for diabetes management. J. Ambient Intell. Smart Environ. 5 (2013) 479-502.

[5] van Hout B, Janssen MF, et al. Interim scoring for the EQ-5D-5L: Mapping the EQ-5D-5L to EQ-5D-3L value sets. Value in Health 2012 Jul-Aug;15(5):708-15.

[6] Khairat S, Garcia C. Developing an mHealth framework to improve diabetes self-management. Stud Health Technol Inform. 2014;205:5337

[7] Kardas P, Mazurkiewicz MR, Kurpas D. Patients' and healthcare professionals' perspective of type 2 diabetes mellitus management: a focus-group study. 4th CODHy - World Congress on Controversies to Consensus in Diabetes, Obesity and Hypertension, Barcelona 2012.

[8] Klonoff DC. The current status of mHealth for diabetes: will it be the next big thing? J Diabetes Sci Technol. 2013 May 1;7(3):749-58.

[9] Abebe NA, Capozza KL, Des Jardins TR et al. Considerations for community-based mHealth initiatives: insights from three Beacon Communities. J Med Internet Res. 2013 Oct 15;15(10):e221. 